December 14, 1990

\title{
Political Business Cycles
}

\begin{abstract}
All market economies display cyclical fluctuations in such key economic variables as unemployment and inflation. These fluctuations are so pervasive that economists devote considerable attention to explaining them. One group of explanations is known as political business cycle (PBC) theories. According to PBC theories, deliberate efforts by incumbent governments to obtain re-election are important inducements to economic fluctuations.
\end{abstract}

This Letter contains a critical review of PBC theories, and concludes with some observations on new theories that emphasize different factors leading to economic fluctuations.

\section{Early version}

In the late 1970s, William Nordhaus of Yale University and Duncan MacRae of The Urban Institute made an early contribution to the advancement of PBC theories. They described how an incumbent administration, in an effort to increase its chances of re-election, tends to pursue policies that lower the unemployment rate close to election time. By so doing, it also generates a temporary inflation. Once elected, the same administration tends to adopt policies designed to offset the inflationary effects of its earlier expansionary policies. Since elections take place at regular intervals, Nordhaus and MacRae predicted that the elections caused cyclical fluctuations in the economy.

This theory has some appealing features. First, it is based on easily understood incentives on the part of governments. That is, governments try to extend their terms in office by gaining popular support. Second, the theory seems able to account for the regularity of some economic fluctuations by associating them with elections.

Nordhaus and MacRae's early PBC theory makes some important assumptions about the behavior of voters and the feasibility of the inflation and unemployment tradeoff. First, it assumes that voters have short memories. That is, voters base their decisions only on the most recent preelection boom. They do not recognize govern- ments' incentives to make the economy look better, or see the recurring pattern of pre-election booms and post-election recessions.

Second, this PBC theory depends crucially on the existence of an exploitable tradeoff between unemployment and inflation, known as the Phillips curve relationship. The theory assumes that government policy can repeatedly reduce unemployment at the expense of more inflation later on. This repetition could happen only if the public were never to catch on, since expansionary government actions, once fully anticipated, are not likely to affect unemployment.

\section{Critique}

The "rational expectations" criticism of Keynesian policy analysis also applies to the PBC theories. The rational expectations school of thought originated in the early 1970s with Robert Lucas, Jr. of the University of Chicago and Thomas Sargent of the Hoover Institution and a Visiting Scholar at the Federal Reserve Bank of San Francisco.

According to the criticism, economic agents make use of all available information in making economic decisions. They also attempt to anticipate government policies that affect their interests. Consequently, government should not be able to exploit systematically a stable tradeoff between unemployment and inflation.

In addition to this conceptual criticism, empirical work by Bennett McCallum of Carnegie-Mellon University directly tested the predictions of the PBC theories. McCallum examined U.S. unemployment data between 1949 and 1974 to see whether the unemployment rate conformed to a general pattern of being low prior to elections and high after elections. He found that the electoral cycle had no significant effect on the pattern of unemployment rates.

In response to these criticisms, $\mathrm{PBC}$ theories have separated into two distinct groups in the 1980s. The first group focuses on the effects of divergent objectives among political parties. The second 
FRBSF

focuses more on the presence of electoral cycles in governmental budgets.

\section{New partisan theory}

The partisan theory derives from the observations that different political parties in the United States (Democratic and Republican) and in European countries (Conservatives and Socialists, among others) seem to have pursued distinctly different economic policies while in office. The differences are most apparent with regard to the relative emphases on unemployment and inflation. Recently, Thomas Havrilesky of Duke University, Jeffrey Sachs of Harvard University and Alberto Alesina of Carnegie-Mellon University, among others, have advanced this partisan view.

In a paper published in 1988, Alesina and Sachs described how electoral cycles can be transmitted to business cycles. According to the authors, people take future government policies into consideration while making current economic decisions. They do so by forming expectations about future policy based on an average of the typical policies of the competing parties. The actual policies of the elected party will necessarily differ from that "anticipated" policy. The resulting "surprise," in theory, would have temporary effects on output.

Alesina and Sachs' reasoning is based on the economic theory that only unanticipated changes in the money supply affect the output of the economy. According to this theory, an unanticipated change in the money supply creates a change in the general price level in the same direction. For example, an unanticipated increase in the money supply would have raised prices. Instead of recognizing the general nature of the price change, producers think that the relative prices of goods have changed because of a shift in consumer demand. Their misperception leads them to alter their output and employment of labor.

The partisan theory therefore predicts that we would observe above-trend growth in the supply of money and output when an expansionary party takes office, and low growth in the money supply and output when the less expansionary party takes office. Also, since the element of surprise is important, the pattern described should be more apparent in the first half of new administrations than in the second half.
To assess these predictions, the chart shows the annual real GNP growth rates for the U.S. from 1947 to 1989 . During the period, the average growth rates of real GNP during the Democratic and Republican administrations were 4.8 percent and 1.3 percent for the first halves, and 4.1 percent and 3.8 percent for the second halves, respectively. These figures seem to support the view that the first halves of each administration were markedly different along party lines during the sample period.

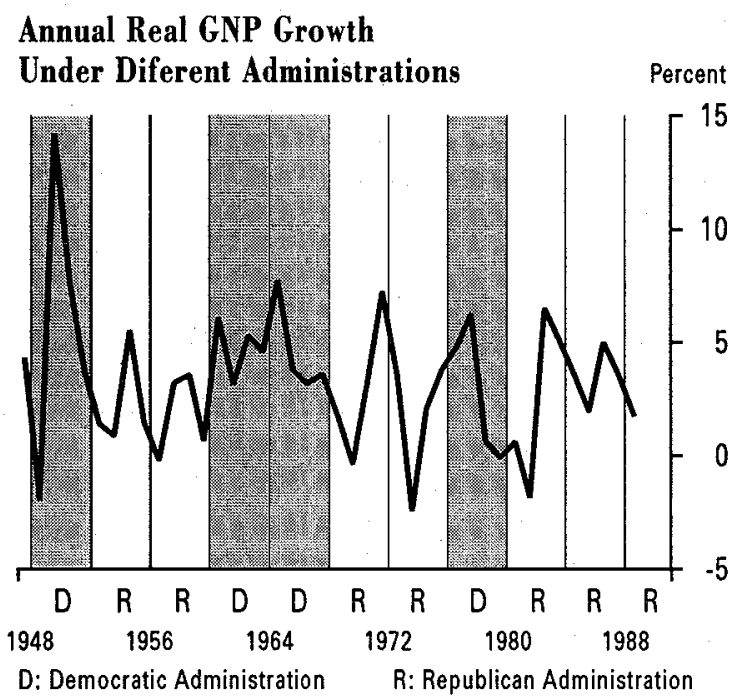

The pattern does not, however, hold with regard to inflation. Inflation measured by the GNP deflator during the Democratic and Republican administrations were 3.1 percent and 4.8 percent for the first halves, and 4.4 percent and 4.3 percent for the second halves, respectively, for the same sample period. Data on inflation and output together imply that the Democratic administrations managed to induce larger increases in output while generating smaller inflations.

This result could be due to possible lags between the time the money supply changed and the time that price changes appeared. However, such a lag violates the assumptions of the money surprise model. It would make money supply changes ineffective at influencing shortterm output because a price change would not immediately accompany a "monetary surprise." People would have time to overcome their surprise in direct contradiction of partisan theory.

Moreover, the view that unanticipated changes in the money supply affect output and prices has become less influential recently. Economists have found that there is not much informational lag between observing shifts in the money supply and those in the general price level. 
Alesina and Sachs also concluded that both the Kennedy and Nixon administrations do not fit the partisan view of the PBC theories. Given that the entire sample consists of four Republican and three Democratic administrations between 1949 and 1984, these exceptions are disconcerting.

\section{New budget theory}

Since the publication of early work on PBC theories, some economists have dropped the focus on the unemployment-inflation tradeoff in favor of a focus on the effects of budget $\mathrm{fi}$ nancing. Among others, Kenneth Rogoff of the University of California at Berkeley and a Visiting Scholar at the Federal Reserve Bank of San Francisco and Anne Sibert of the University of Kansas have focused on budget cycles that result from deliberate attempts by incumbent governments to influence the economy in their favor.

A government can finance its budget by a combination of raising tax revenue and printing money, assuming that the government controls the monetary authority. Rogoff and Sibert define voter preferences for a competent government in terms of a concern for a government that can provide services at a smaller cost to the public. They assume that the public can discern the true performance of government and the size of seignorage (the revenue from creating money) only after a time lag. The incumbent government, in their view, tries to impress voters near election time by lowering taxes and increasing spending. The public, in turn, interprets these actions as evidence of an effectively operating government.

In sum, incumbent governments have incentives to finance the budget with relatively less tax revenue, which voters recognize immediately, and higher seignorage, which voters do not identify until after the election. Elections held at regular intervals would therefore produce economic cycles.

The budget cycle approach is more plausible than early PBC theories because it focuses on policy variables that are under the direct control of government. However, Rogoff and Sibert may have defined voter preferences too narrowly. They do not take into account preferences for the size of government, or spending priorities (such as, defense versus social welfare).

Also, their study presupposes the existence of extensive coordination between the incumbent administration and the central bank that determines monetary policy. Such coordination may occur in countries where the government directly controls the central bank, but not in the U.S. where the Federal Reserve is more independent. Chairman Paul Volcker's pursuit of a disinflationary monetary policy in the early 1980 s despite pressures from the Reagan Administration is one example.

Monetary policy alone is not central to all studies of budget cycles, however. Recent studies by Rogoff focus exclusively on taxation behavior. Nevertheless, even with regard to taxes, proponents of the budget cycle theory have yet to establish a firm link to fluctuations in broad economic activities.

\section{Conclusion}

The problems of PBC theories illustrate growing doubts in macroeconomics about the central role of fiscal and monetary policies in driving economic fluctuations. Real Business Cycle theories offer a different perspective whose acceptance is growing.

Real Business Cycle (RBC) theories deny a central role to easily identifiable factors, such as the deliberate actions by governments, in causing fluctuations in economic activities. According to the RBC view, prices are flexible enough and people's expectations, on average, are accurate enough to mitigate the real effects of policies. Instead, the theories assign the key role in economic fluctuations to the dynamic effects of individual behavior. They focus on, for example, how people react to changes in technology over time, how they change decisions about when to consume, and how much time to spend at leisure or at work.

Although not settled yet, the debate over causes of economic fluctuations has moved away from the factors central to PBC theories. The emphasis among economists has shifted toward an explanation of economic fluctuations as the equilibrium outcome of a well-functioning market economy. This contrasts with the explanation that government policies aimed at managing aggregate demand cause fluctuations in inflation, unemployment, and output.

\section{Chan Guk Huh}

Economist

Opinions expressed in this newsletter do not necessarily reflect the views of the management of the Federal Reserve Bank of San Francisco, or of the Board of Governors of the Federal Reserve System.

Editorial comments may be addressed to the editor or to the author. ... Free copies of Federal Reserve publications can be obtained from the Public Information Department, Federal Reserve Bank of San Francisco, P.O. Box 7702, San Francisco 94120. Phone (415) 974-2246. 
Research Department

Federal Reserve

Bank of

\section{San Francisco}

P.O. Box 7702

San Francisco, CA 94120 